\title{
New Insights of Wear Behavior Analysis on Low Temperature Treated AISI 253MA Stainless steel Material by Gas Nitriding Process
}

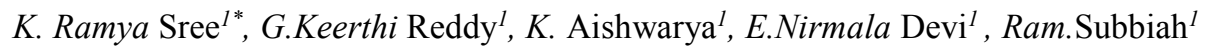 \\ ${ }^{1}$ Mechanical Engineering Department, Gokaraju Rangaraju Institute of Engineering \& Technology, Hyderabad, India
}

\begin{abstract}
AISI 253MA Stainless steel samples were treat with the gas nitrating process at low heat around $450^{\circ} \mathrm{C}$. It was seen that all-inclusive austenite stage exist when it is nitrade to 8 hours and post addition at time of nitrading to 16 hours the mix of ferrites and progressively substance of nitrogen was gathered in the following layers. Farther nitrading to 24 hour it has seen at $\mathrm{Cr}-\mathrm{N}$ stage was discovered and turns the steel progressively firmer superficially. Erode tests were led by tribological wear testing machine to examine the tribological wear loss. Volume wear was found to be least in 18 hours test which demonstrated better improvement of wear improvement. High hardness were found in $24 \mathrm{hrs}$ showing a hardness of $1080 \mathrm{Hv}$. The sample nitrided to 24 hours exhibited better wear resistance, high hardness and low wear loss as well as low volume wear loss. Assessment examinations of nitrided test samples were investigated under scanning electron magnifying analysis.
\end{abstract}

\section{Introduction}

AISI 253MA Austenitic stainless steels, known for its remarkable resistance to corrosion that has created expanded exposure in various applications. Be that as it may, their terrible tribological and mechanical properties were found to be very low, their applications are very limited[1-3]. Traditional NACL shower Nitrading has neglected to improve the case profundity, wear opposition and rigidity of the steel. so vaporous nitrading is extraordinary compared to other procedure to advance the protection from wear and erosion improbable plasma nitrading additionally been used to improve the hardness of the hardened steel however the procedure is taking additional time, lopsided dissemination of nitrogen, stream of nitrogen gas was poor[4]. Whereas gas nitrading is straightforward and stable procedure requires low support costs, charge of fuel in the heater is faster than different procedures. Especially austenitic steels are all the more regularly treated with the nitrading procedure. Hardened steels are present day materials. Since the time they opened up to enterprises, their utilization has continually reached out into new applications [5-7].

In order to utilize the treated steels, in building applications, it is important to know the properties, their abilities in regards to erosion obstruction, the accessibility of item structures and surface completions hardened steels are being utilized for both consumption and the warmth opposing applications. Treated steel is the conventional name for various steels utilized basically for their protection from corrosion. Gas nitrading is the best technique for nitrading the tempered steels contrasted with different procedures. AISI 253MA material has been once in a while used material inorder to know its properties and the conduct of this steel it is treated under the low temperature i.e., at $450^{\circ} \mathrm{C}$ [8-10]. Right now these steel were treated with low temperature gas nitrading to get S-stage. Later on dry sliding wear conduct was discover with the assistance of pin on circle mechanical assembly metallographic examines were led with filtering scanning electron microscope magnifying instrument[11].

It is important to know the utilization of stainless steel in building applications, their properties, their capabilities regarding corrosion resistance, the availability of product forms and surface finish. Stainless steels are applicable for corrosion, warm resisting applications. Stainless steel satisfies all these requirement in combination with good mechanical properties and manufacturing characteristics and hence make it an indispensable tool for the Designers[12-15]. Stainless steels shows a stable growth when compared to carbon based steels in most of the cases showing relatively unfamiliarity to designer. The alloy were milled for all ductile applications like sheets - plates, bars - wires - tubes to be used in cookware, cutlery, hardware, surgical instruments, major appliances,

* Corresponding Author. ramyasreekeerthi@gmail.com 
industrial equipment and building material in skyscrapers and large building [16,17]. Stainless steels pursue to have high oxidation resistance at artificial and natural environments $[18,19]$. Surface hardness can be increased by diffusion of carbon or nascent nitrogen. In carburizing, the problem of sensitization is encountered which results in reduction of corrosion resistance, whereas in nitriding hard complex nitrides of $\mathrm{Fe}-\mathrm{Cr}$ are formed which elaborates the hardness on the surface, case depth and microstructure. Stainless steels have sufficient amount of chromium present, so that a passive film of chromium oxide forms which prevents further corrosion [20].

\section{Experimental Details}

\subsection{Wear Tests}

The elemental compositions of AISI 253 MA Stainless steel was found to be with a maximum range of carbon $0.1 \%, \quad 0.81 \%$ manganese $0.03 \%$ sulphur, $0.04 \%$ phosphorus, $1.8 \%$ silicon, $12 \%$ nickel, $22 \%$ chromium and the remaining composition of iron. Cylindrical pins were selected and the measurements were found to have measurement lengthwise and width of across 12 $\mathrm{mm}$. Before investigation, the samples were cleansed by Ultrasonic method [21-23]. For gas nitrading process, 3 pins were utilized and the 3 specimens were nitraded by smelling $\mathrm{NH}_{3}$ gas for $8 \mathrm{hrs}, 16 \mathrm{hrs}$ and 24 hrs of treatment time. Initially, the specimens were placed on the holder, later gas was streamed at the pace of $8 \mathrm{cu} . \mathrm{m} / \mathrm{hr}$. The nitrogen elements gets incited on steel outer layer. Wear testing machine namely pin on disc tribo-meter shown in the Fig 1 and Fig 2 was utilized for leading the wear test. With the plate pivoted at $600 \mathrm{rpm}$, a heap of $50 \mathrm{~N}$ is applied for 3 minutes under the sliding conditions without any lubricating agent $[3,4]$.

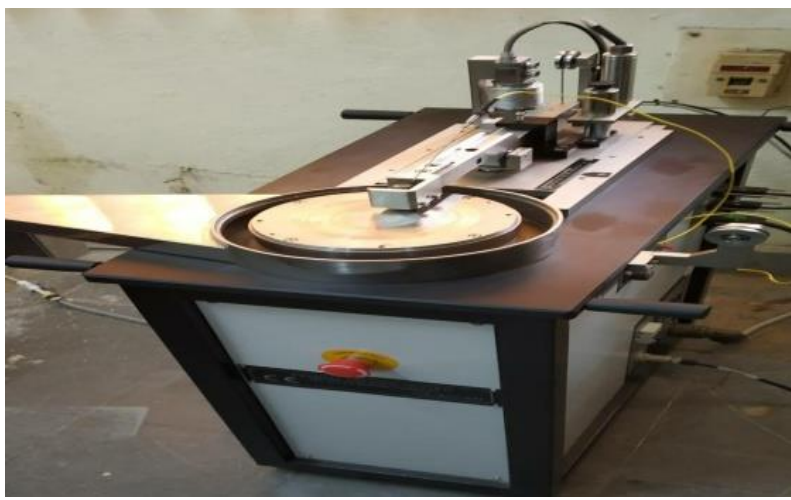

Fig 1. Wear Test Tribometer

The applied weight reduction is deducted by observing the distinction between by applying the load and after releasing the load. Thus loss in wear and volume wear loss were monitored. Minute perceptions and morphology of the surface were noticed utilizing filtering SEM. The wear loss to volume were found to be as $5.98 \mathrm{~mm}^{3}$ in an untreated specimen. The volume wear loss of gas nitraded samples for $8 \mathrm{hrs}, 16 \mathrm{hrs}, 24$ hrs was founded at as $4.41 \mathrm{~mm}^{3}, 2.26 \mathrm{~mm}^{3}$ and 1.12 $\mathrm{mm}^{3}$ respectively.

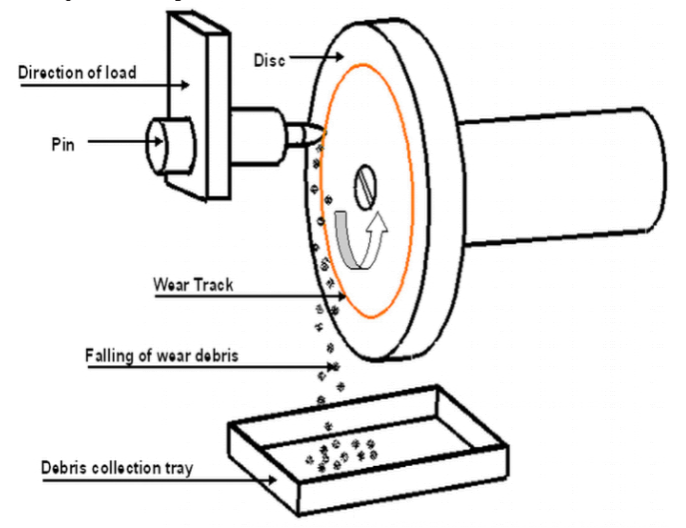

Fig 2. Layout of Wear Test Process [11]

Gas Nitrading (GN) strategy were utilized to progress the hardness of an austenite hardened stainless steel structure AISI 253MA Stainless Steel. In this manner nitrading process were accomplished for to hours on AISI $253 \mathrm{MA}$ between $450-550^{\circ} \mathrm{C}$. The gas nitrading procedure were intended to restrain the white layer in two different stages. This process builds surface hardness varying $218 \mathrm{H}_{\mathrm{v}}$ in a non-treated sample of AISI 253MA to $1080 \mathrm{H}_{\mathrm{v}}$ treated to $24 \mathrm{hrs}$. It was examined a thick and institutionalized nitride buildup on the AISI 253MA is delivered by depositing the gas on the surface level. The tribolgical behaviour infers that, the gas nitrated covering on AISI 253MA expels grip bonds and reveals a delicate surface. This nitrading process has superb wear obstruction on the surface of AISI 253MA substrate [6-11]. The result demonstrates attributable to a solid nitrading limit of alkali gas, S-stage were formed as encompassing austenite. The phase of harmony, $\mathrm{Cr}-\mathrm{N}$ were formed in two particular strategies by disintegrating the S-layer. Because of steady precipitation of solids, S-layer attributable to a more prominent nitradizing limit; the other was brought about by broken fine precipitates on the austenite surface, bringing about a decent lamellar zone of austenite and $\mathrm{Cr}-\mathrm{N}$.

\section{Results and Discussions}

\subsection{Surface Morphology investigation}

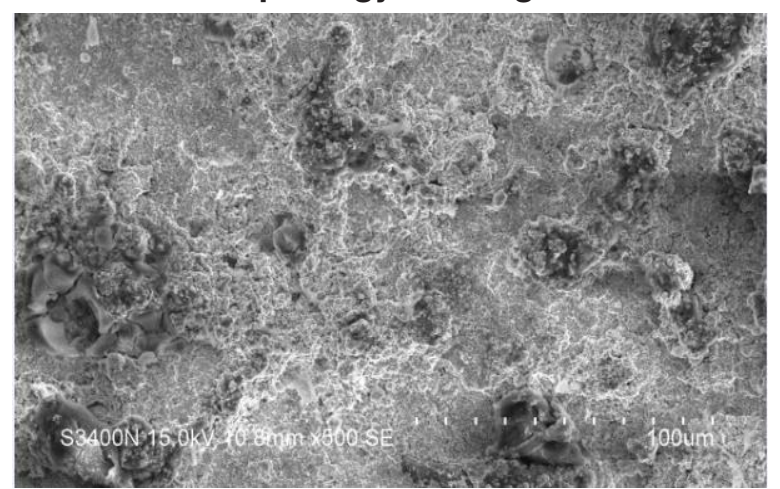

Fig 3 AISI 253MA SS in Untreated Stage 


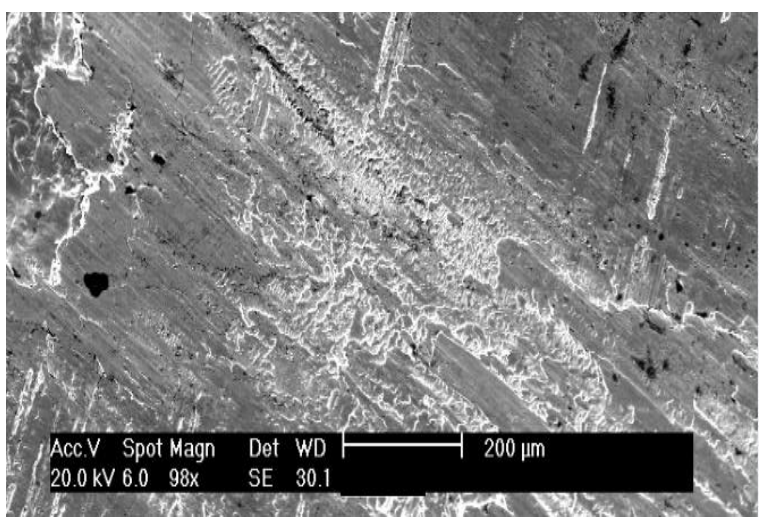

Fig 4 Gas Nitrided Specimen - 8Hrs Wear Tested

It was observed that there were huge removals of material in an un-treated sample as shown in the Fig 3. Minute cracks with micro etches pits were noted down in surface of un-treated specimen, the material peel-off were noted. Because of poor strength, poor hardness of material, applied load with speed during the wear test. From the Fig 4, it was noted that, Nitrogen have effective solid solution strengthener than carbon and improves the grain size. Nitrogen is a strong austenitic stabilizer by reducing the amount of nickel required for stabilization [15]. Nitrogen alloying also reduces the ability of ferrite compounds formation. The peel of material was found to be very low as there is an increase in hardness and strength of material compared with sample subjected to untreated one.

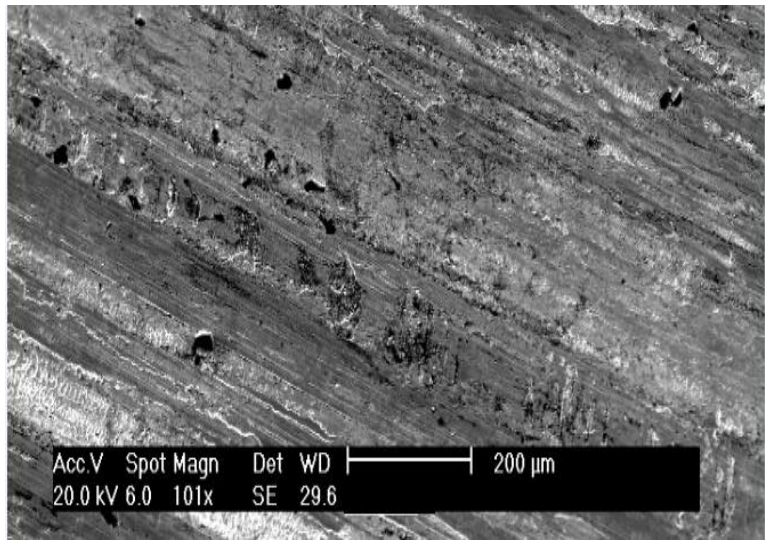

Fig 5. Gas Nitrided Specimen - 16 Hrs Wear Tested

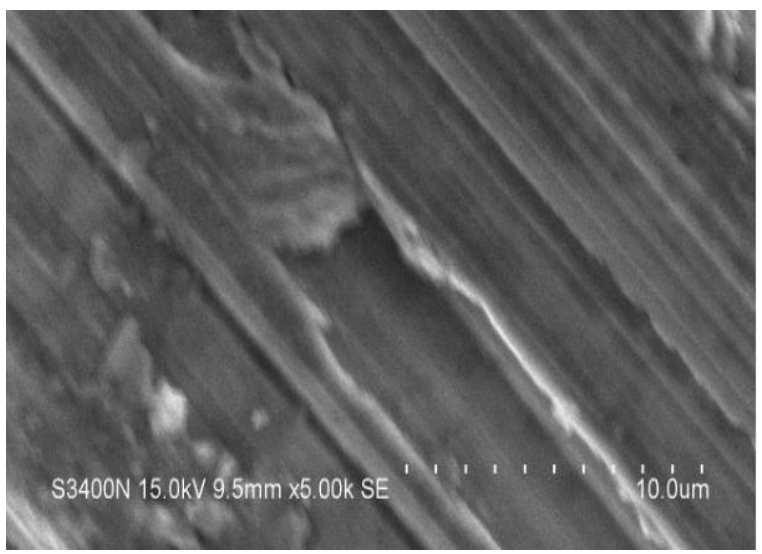

Fig 6. Gas Nitrided Specimen - 24 Hrs Wear Tested
The nitrogen alloy contributes significantly in improvement of sliding wear and corossion resistance of stainless steels as shown in the Fig 5. Since nitrogen alloy have higher solid solubility than carbon, it decreases the material strengthening level. At normal temperature, the addition of nitrogen to stainless steel have importance to fatigue resistance subjected to low cyclic stress. This nitrogen alloy has an improving effect on mechanical properties of the steels until the solubility of nitrogen is reached [18]. The hardness was observed to be incremented several times compared to the untreated samples due to the lattice expansion created by the super saturation of nitrogen as shown in the Fig 6. There were found to be very less peel of material, improving the resistance to wear and material life.

\section{Conclusions}

Few contributions are worked out with AISI 253 MA Stainless steel under Gas nitrading process. Taking as a challenge for the high temperature applications like components subjected to sea water, turbine blades this material was tended to low temperature gas nitriding process. The following are the conclusion noted from the work done.

(i)From the surface morphology examination, a white region acquired known to be S-stage were formed as an extended austenite. Further proceeding with the treatment process, it was extended to $\mathrm{Cr}-\mathrm{N}$ stage, exceptionally hard nitrides comprises of ferrite, and nitride blends. A moderately plain thick composite layer is identified in all gas nitraded samples. The untreated sample wear loss was found to be $6.25 \mathrm{~mm}^{3}$ and the gas nitraded sample for 18 hours was found to be $1.12 \mathrm{~mm}^{3}$.

(ii)The impervious to wear is seen as progressively articulated and the explanation behind is credited to the compound zone forming a hardened layer. For gas nitrading test exposed to 8 hour, the hardness was noted as $732 \mathrm{Hv}$, For $16 \mathrm{hrs}$ the hardness were found to be as $919 \mathrm{HV}_{\mathrm{V}}$ and For $24 \mathrm{hrs}$ the hardness were found to be as $1080 \mathrm{H}_{\mathrm{V}}$. The stage layer of un-treated sample comprises of $\alpha$-ferrite and different elemental components, when the specimens are treated between 16 hours to 24 hours. It was noted down in improvement of forming compound layer $\mathrm{Fe} 4 \mathrm{~N}$ and CrN stages.

\section{References}

1. A.Somers Marcel, Christiansen Thomas, PED, 26 (2007).

2. A.Staynes, T.Bell HTMM (1979).

3. A.Staynes, HTTM, 23 (1996).

4. A.Toro, AP.Tschiptchin Scripta Materialia, 63, (2010). 
5. AV.Belyi, V.A.Kukareko, S.G.Sandomirski Metal Science and HeatTreatment, 51(2009)

6. C.Arlos Mario Garzon, H.Thomas, J. Francisco Dosantos, Wear, 259 (2005).

7. C.H.Hsu, C.K.Lin, K.H.Huang, K.L.Ou Surface Coatings and Technology, 88 (2012).

8. C.X.Li, T.Bell, Materials Processing Technology, 168 (2005).

9. C.Zhao, C.X.Li, H.Dong, T.Bell, Surface Coatings and Technology, 201 (2006).

10. C.Z.Christiansen Thomas, A.J.Marcel, Somers, Surface Engineering, 9 (2006).

11. P. Rajendran, A. Devarajuv, Materials Today: Proceedings 5 (2018).

12. Tummala Suresh Kumar, Kosaraju Satyanarayana, Materials Today: Proceeding, 26(2020).

13. Ghorabaei AS, Banadkouki SSG.Mater Sci Eng A 73 (2017).

14. Bobadilla M, Tschiptschin A. Mater Res 4 (2015).

15. Hao YS, Liu WC, Li J.,Mater Sci Eng A,68 (2018).

16. Ren XP, Li SX, Xiong ZP. J Manuf Process, 24 (2018).

17. Qiao YX, Chen J, Zhou HL, Wang YX. Wear 7(2019).

18. Graham CD, Lorenz BE.J Magn Mater 8 (2018)

19. Suresh Kumar T, Sankar V, 2011 IEEE India Conference, INDICON, 2011

20. Baba H, Kodama T, Katada Y. Corros Sci 407 (2002)

21. Md Sumair Ur Rahman, L.Jayahari Materials Today: Proceedings, 5(2018),

22. L Jayahari, B Balunaik, A Kumar Gupta, S.K. Singh Materials Today:Proceedings, 2 (2015)

23. Ratna Deepika M, Satyanarayana kosaraju, K. Arul Raj, N.Sateesh, Materials Today: Proceedings, 5(2018), 